Paulina Maria Angela C. Villar, MD, MBA

Ryan U. Chua, MD

Ruby P. Robles, MD

Department of Otorhinolaryngology

Head and Neck Surgery

The Medical City
Correspondence: Dr. Ruby P. Robles Department of Otorhinolaryngology Head and Neck Surgery

The Medical City

Ortigas Avenue, Pasig City 1600

Philippines

Phone: (632) 86356789 local 250

Fax: (632) 86873349

Email:ruby_robles_ph@yahoo.com

The authors declared that this represents original materia that is not being considered for publication or has not been published or accepted for publication elsewhere in full or in part, in print or electronic media; that the manuscript has been read and approved by the authors, that the requirements for authorship have been met by each author, and that the authors believe that the manuscript represents honest work.

Disclosures: The authors signed disclosures that there are no financial or other (including personal) relationships, intellectual passion, political or religious beliefs, and institutional affiliations that might lead to a conflict of interest.

\title{
Smell Training in Prolonged COVID-19 Post- Infectious Olfactory Dysfunction: A Case Report
}

ABSTRACT

Objective: To report the case of a woman who underwent smell training for post-infectious olfactory dysfunction presumably from COVID-19.

\section{Methods:}

$\begin{array}{ll}\text { Design: } & \text { Case Report } \\ \text { Setting: } & \text { Tertiary Private Training Hospital } \\ \text { Patient: } & \text { One }\end{array}$

Result: A 41-year-old woman who developed olfactory dysfunction attributed to COVID-19 underwent smell training. At baseline, her responses were mostly "no smell," and those reported as "can smell a bit" were rated as distorted. After three months, she could now smell items that she previously could not smell, but these smells were still distorted. At the time of this writing, she was on her $4^{\text {th }}$ month of smell training.

Conclusion: Although we cannot rule out spontaneous resolution of anosmia in our patient, we would like to think that smell training contributed to her recovery of smell.

\section{Keywords: Anosmia; COVID-19; Olfactory Bulb; Olfaction Disorders}

Viruses that cause upper respiratory tract infections (such as rhinovirus, coronavirus, parainfluenza virus) are known to cause a condition called post-infectious olfactory dysfunction (PIOD).' Patients with this condition often continue to experience impaired smelling capabilities despite the resolution of other symptoms. Olfactory dysfunction has been recognized by the Center for Disease and Control Prevention (CDC $)^{2}$ and the World Health Organization (WHO) as a symptom of COVID-19 caused by SARS-CoV-2. Initially, it was described by Lechien et al. as acute sudden onset of olfactory dysfunction without nasal congestion or obstruction, ${ }^{4}$ but as more studies emerged, its characteristic and duration seem to be more varied with some cases not having complete resolution. ${ }^{5}$ Smell training has been known to improve olfactory sensitivity and is recommended for patients with post infectious olfactory dysfunction, but to the best of our knowledge, based on a search of HERDIN Plus, the ASEAN Citation Index, the WHO Global Index Medicus (Western Pacific Region Index Medicus and Index Medicus of the South East Asia Region), and PubMed (MEDLINE, PubMed Central) using the keywords "olfactory dysfunction", "anosmia", "post-infectious olfactory dysfunction", "COVID-19", we found no published studies on patients with persistent olfactory dysfunction from COVID-19 infection. We report the case of a woman who underwent smell training for prolonged post-infectious olfactory dysfunction presumably from COVID-19. 


\section{CASE REPORTS}

\section{CASE REPORT}

A 41-year-old woman complained of loss of sense of smell at the start of the COVID-19 pandemic in the Philippines. She had no known exposure to a confirmed COVID-19 case and no recent travel history. Although she had mild intermittent allergic rhinitis she had not experienced any changes or dysfunction in her sense of smell before this. Aside from allergic rhinitis, she also had a history of mild epilepsy 18 years prior, with no recurrence and no maintenance medications (corroborated by a normal electroencephalography). She previously smoked one cigarette per week for four years but stopped one year before this present illness.

She had just returned to work from maternity leave on March 2, 2020, when after one week (March 9, 2020), she experienced sore throat and nasal congestion which she attributed to her allergic rhinitis. On day nine (March 17, 2020), she developed post-nasal drip which she treated with her usual allergy medication -fluticasone furoate, one spray per nostril once a day, and loratadine $10 \mathrm{mg} / \mathrm{tab}$ once a day, both of which were only used as needed. She also started to develop severe persistent frontal headache and non-productive cough.

Thirteen days after her first symptoms (March 21, 2020), she lost her sense of smell and taste. She also developed pain in her left maxillary area, prompting teleconsultation with a general practitioner. She was prescribed prednisone $20 \mathrm{mg} / \mathrm{tab}$ one tablet twice a day for three days followed by one tablet thrice a day for 3 days; cefuroxime $500 \mathrm{mg} / \mathrm{tab}$, one tablet twice a day for five days, and salbutamol nebulization. All of her symptoms resolved after five days, except for anosmia.

Two months after onset of her first symptoms (June 1 to 6, 2020), she developed phantosmia. She would smell smoke despite there being no evidence of smoke or other odorant in the immediate area. On June 4, 2020, she consulted an ENT specialist. Because all her other COVID-19 symptoms had resolved, she was no longer a candidate for reverse transcriptase polymerase chain reaction (RT PCR) assay based on the protocols at that time. Nasal endoscopy showed unremarkable results with no note of mucus discharge, polyps, obstructive septal deformity, or abnormalities in the olfactory cleft. A paranasal magnetic resonance imaging (MRI) and cranial MRI (requested by a co-managing neurologist) showed symmetrical atrophy of the olfactory bulbs. (Figure 1) The radiographic report measured the right olfactory bulb at $0.8 \mathrm{~mm}$ and the left at $1.1 \mathrm{~mm}$ in maximum thickness. The patient scored 22/40 (corresponding to severe microsmia) on the University of Pennsylvania Smell Identification Test (UPSIT). She was prescribed oral steroids $40 \mathrm{mg} /$ day for 21 days with decreasing dose, omega 3 supplementation taken once a day, and advised her to continue fluticasone furoate, one spray once a day. Two months and 2 weeks after her first symptom (3rd week of June), she began smell training which consisted of inhaling 4 scents (clove, ylang-ylang, lemon, and eucalyptus) for 20 seconds each, twice a day (before breakfast and before bedtime). At the start of smell training, she underwent a modified baseline smell evaluation. Using commonly encountered household items, she was asked to rate whether she could detect the smell ("can smell"), was slightly aware of the smell ("can smell a bit"), or could not smell at all ("no smell"); and then determine if the smell was as she expected it to be, or if it was distorted. The items were listed in categories: fruit, vegetable, herbs and spices, nuts, beverages, cleaning/grooming items, personal items, and items seen inside and outside the house. At baseline, her responses were mostly "no smell," and those she reported she "can smell a bit" were rated as distorted. She subsequently recorded what scents she could smell around her household, monitoring her progress daily in a smell journal. Weekly online consultations documented and assessed improvement in terms of smell identification, discrimination, and threshold.

Three months after the first symptom (July 10, 2020), a SARSCoV-2 electrochemiluminiscence immunoassay (ECLIA) antibody test revealed COVID-19 IgG antibodies corresponding to either the recovery or convalescence phase. Although no repeat UPSIT was performed (due to financial constraints), the patient reported that she could now smell items that she previously could not smell during the modified baseline smell evaluation, but these smells were still distorted or not how she expected them to be. At the time of writing of this paper, she was on her $4^{\text {th }}$ month of smell training.

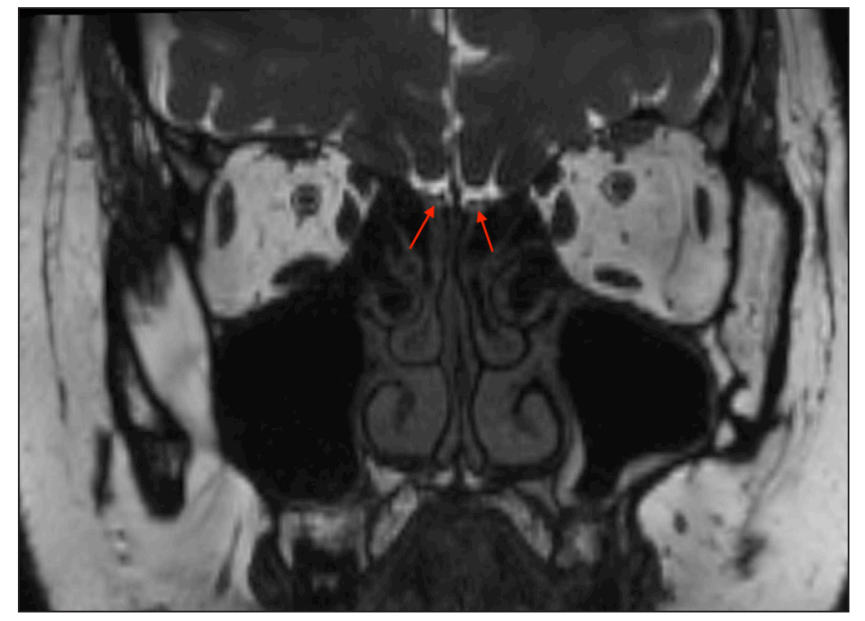

Figure 1. MRI of the Olfactory Bulbs (T2 weighted CISS sequence, coronal slice). There is symmetrical flattening with apparent loss of the normal oval configuration of the olfactory bulbs (red arrows). The right olfactory bulb measures $0.8 \mathrm{~mm}$ while the left measures $1.1 \mathrm{~mm}$ in maximum thickness.

\section{DISCUSSION}

In this case, we described a patient who had symptoms attributed to allergic rhinitis that eventually were considered as post-infectious olfactory dysfunction most likely due to COVID-19. Unlike most cases reported in the literature, she did not undergo RT PCR testing. At the onset of her smell dysfunction, it was not yet well known that olfactory disturbances were part of the symptomatology of COVID-19 and she did not consult or have a test done immediately. When she finally did consult, the patient was mostly asymptomatic except for anosmia and 14 days had elapsed from symptom onset. Protocols in place at the time reserved viral RT PCR testing to diagnose current infections. ${ }^{6}$ However, antibody testing could determine previous COVID-19 because 


\section{CASE REPORTS}

antibodies only develop one to three weeks after infection. ${ }^{7}$ Three months after onset of symptoms, our patient had an ECLIA antibody test (that has an $82.4 \%$ sensitivity if used at least 14 days from onset of symptoms, with lower sensitivity anytime earlier). ${ }^{7}$ Although the ECLIA test is not recommended for the diagnosis of COVID-19, it supports the possibility of a past COVID-19 infection to explain her abrupt and severe olfactory dysfunction.

Our patient experienced nasal congestion which resolved before the onset of her olfactory dysfunction. She also experienced frontal headache and maxillary pain together with her loss of sense of smell. Although anosmia in COVID-19 usually presents suddenly without nasal congestion or evidence of nasopharyngeal abnormalities, this does not mean that it exclusively occurs without other ear, nose, throat symptoms. A study describing features of anosmia in COVID-19 by Klopfenstein et al. noted that 57\% presented with rhinorrhea and 30\% had nasal obstruction, while $84 \%$ also experienced headache along with other symptoms of fatigue, myalgia, fever and cough. ${ }^{8}$

The olfactory bulbs of our patient appeared atrophic on paranasal and cranial MRI. Earlier studies that documented COVID-19 anosmia with supporting MRI studies showed normal olfactory bulbs., ${ }^{9,10}$ However, Chiu et al. showed evidence of olfactory bulb atrophy in a 19-year-old RT PCR confirmed case of COVID-19 compared to their patient's pre-COVID MRI images. ${ }^{11}$ Other studies show that olfactory bulb volume correlates with olfactory function. ${ }^{12-15}$ Unfortunately, only olfactory bulb thickness (and not volume) was measured in our case, and the impression of olfactory bulb atrophy was based on radiologist experience rather than standardized protocols. Moreover, we had no pre-morbid MRI images available for comparison.

The exact mechanism of olfactory loss in COVID-19 is still debatable but studies reviewed by Han et al. have made speculations based on the understanding of respiratory viruses. ${ }^{16}$ Similarly, Butowt et al. explored and considered four different scenarios that could explain smell dysfunction in COVID-19: nasal obstruction/congestion and rhinorrhea, loss of olfactory receptor neurons, brain infiltration affecting olfactory centers, and damage of support cells in the olfactory epithelium. ${ }^{17}$ Given that they analyzed mostly cases of isolated acute onset olfactory dysfunction, they focused on the entry, infection, and death of the sustentacular cells but not on the olfactory receptor neurons that have the capacity to regenerate. ${ }^{17}$ Furthermore, they observed that compared to western countries, regardless of whether it is due to underreporting, or to mutations, or genetic variability of the virus and host, there seems to be a difference between the presentation of anosmia in western and east Asian cultures. ${ }^{17}$

The UPSIT is a well-validated 40-odorant test that objectively measures the sense of smell of a patient and can be used as a biomarker for COVID-19 especially for patients who have mild to moderate symptoms. ${ }^{18} \mathrm{~A}$ study by Moein et al. noted that some degree of smell loss was present in nearly all COVID-19 patients near the end of their acute recovery period, and suggested that quantitative smell tests might serve as a rapid and inexpensive alternative screening tool for COVID-19 among large numbers of people. ${ }^{18}$ However, because most smell tests would take relatively longer to accomplish compared to a temperature check, and since they cannot account for pre-existing olfactory loss, ENT UK noted that wide scale mass testing would have limited application as a screening tool. ${ }^{19}$ The UPSIT itself may have limited use in the Filipino context, as Evidente et al. found that only 25 (out of 40) test odor items were familiar (both in nature and smell) to $95 \%$ of the patients they surveyed in a study of smell dysfunction among Filipinos with X-linked dystonia-parkinsonism in the Panay Islands. ${ }^{20}$ The 15 unfamiliar odors excluded from the culturally corrected UPSIT were cherry, clove, fruit punch, licorice, cinnamon, cedar, gingerbread, lilac, turpentine, peach, dill pickle, lime, wintergreen, pine, and natural gas. ${ }^{20}$ A Filipino version of UPSIT developed by David et al. in $1994^{21}$ was not used in this patient as the UPSIT was more readily accessible.

New-onset anosmia in COVID-19 is a relatively novel condition and local protocols for management have not yet been established. However, as early as May 19, 2020 recommendations for management were published in the ENTUK website (https://www.entuk.org/guidelinemanagement-covid-19-anosmia). An algorithm can be found in this website recommending smell training for patients with anosmia that persisted for more than two weeks. Smell training has been known to improve olfactory sensitivity through structured, short term exposure to odors. ${ }^{22}$ Anosmic patients are advised smell training by being exposed to four odorants twice a day over three months, and then another four odorants in the next three months. ${ }^{23}$ This therapy to enhance or amplify olfactory recovery was proposed by Hummel et al., ${ }^{22}$ speculating that it improves odor thresholds (and by implication the architecture of the peripheral olfactory system), and that olfactory training changes the processing of olfactory information. Based on their 2009 study, patients who underwent smell training noted increases in their olfactory function over baseline compared to those who did not. ${ }^{22}$ A follow up study in 2015 reported increased improvement in smell discrimination and identification when scents were changed after 3 months. ${ }^{23}$ Smell training traditionally utilizes four scents - clove, rose, lemon, and eucalyptus. ${ }^{22}$ In our case, rose was changed to ylang-ylang as it was more readily available and less expensive. The main extract of rose in essential oils is phenylethyl alcohol which gives a mild rose odor and is commonly used as a test odorant. Ylang-ylang on the other hand, contains 2-phenyl ethyl acetate, a chemical derived from condensation of acetic acid and phenylethyl alcohol which gives off a rose and honey scent. ${ }^{24}$ Aside from practicality, substituting ylang-ylang for rose was also based on the principle of "odor prism" by Henning where primary odor categories were identified: flowery, foul, fruity, and aromatic, burnt, and resinous. ${ }^{22}$ The traditional scents used by Hummel et al. were chosen to represent the said odor categories. ${ }^{22}$ Although our patient was not able to undergo a repeat UPSIT, she recorded her progress based on threshold/detectability and likeness (how similar the smell was to the way she remembered it before). After shifting scents on the fourth month, she reported increased intensity or likeness in her sense of smell. In terms of threshold, she was able to smell the scents from the amber test jars without having to bring them as close to her nose as before. However, there were still scents from the baseline evaluation that she could not identify.

Given that most documented cases of COVID-19 anosmia recover completely, studies regarding olfactory training in COVID-19 are 


\section{CASE REPORTS}

largely unavailable. This makes our documentation of this patient's therapy with smell training even more valuable, as it may serve as a reference for other COVID-19 patients that also experience a prolonged course of anosmia or hyposmia that does not resolve spontaneously. AbScent, ${ }^{25}$ a UK-based organization dedicated to raising awareness of anosmia, provides online instructional materials on how to conduct smell training at home based on the therapy designed by Hummel et al. ${ }^{22}$ This may be helpful to those unable to seek professional help due to the pandemic. As mentioned earlier, aside from performing smell training daily, the patient also kept a smell journal which aided in documenting her progress or the extent of smell distortion, as well as providing psychological insight into the prolonged course of parosmia as improvements may seem too subtle for patients such as her to recognize. ${ }^{25}$

There are several limitations to this case report. First and foremost, we cannot attribute resolution of anosmia to any intervention, including smell training, as spontaneous resolution of anosmia and recovery of smell have to be considered. Moreover, our patient was not tested for antigens at the onset of her anosmia and the antibody test eventually utilized could only detect past infection. Future studies can document COVID-19 at the outset, especially now that anosmia is a recognized symptom. Furthermore, olfactory bulb volume was not measured conventionally, and atrophy was based on subjective experience. Standard acquisition of MRI images may facilitate measurement of olfactory bulb in future studies of olfactory function. Finally, our therapy (including substitution of odorants, documentation of progress, tele-monitoring and reporting) was personalized and subjective, with no objective corroboration. Standardized procedures, reporting and documentation of patients undergoing smell training, especially for COVID-19, may contribute to better understanding and improving their management, and contribute toward developing a local smell training protocol. Ultimately, a case-control series (or even a randomized controlled trial) may demonstrate the role of smell training in post-infectious olfactory dysfunction.

In summary, we reported the case of a patient who underwent smell training for prolonged post-infectious olfactory dysfunction presumably from COVID-19. Although we cannot rule out spontaneous resolution of anosmia in our patient, we would like to think that smell training contributed to her recovery of smell.

\section{ACKNOWLEDGEMENTS}

We would like to thank our patient who voluntarily shared her condition and experience for this case report.

\section{REFERENCES}

1. Suzuki M, Saito K, Min WP, Vladau C, Toida K, Itoh H, et al. Identification of viruses in patients with postviral olfactory dysfunction. Laryngoscope. 2007 Feb;117(2):272-277. DOI: 10.1097/01 mlg.0000249922.37381.1e PubMed PMID: 1727762; PubMed Central PMCID: PMC7165544.

2. Lechien JR, Chiesa-Estomba CM, De Siati DR, Horoi M, Le Bon SD, Rodriguez A, et al. Olfactory and gustatory dysfunctions as a clinical presentation of mild-to-moderate forms of the coronavirus disease (COVID-19): a multicenter European study. Eur Arch Otorhinolaryngol. 2020 Aug;277(8):2251-2261. DOI:10.1007/s00405-020-05965-1 PubMed PMID: 32253535; PubMed Central PMCID: PMC7134551.

3. Coronavirus disease (COVID-19) [Internet]. Who.int. 2021 [cited 2021 Apr 29]. Available from: https://www.who.int/emergencies/diseases/novel-coronavirus-2019/question-and-answershub/q-a-detail/coronavirus-disease-covid-19.

4. Lechien JR, Chiesa-Estomba CM, De Siati DR, Horoi M, Le Bon SD, Rodriguez A, et al. Olfactory and gustatory dysfunctions as a clinical presentation of mild-to-moderate forms of the coronavirus disease (COVID-19): a multicenter European study. Eur Arch Otorhinolaryngol. 2020 Aug;277(8):2251-2261. DOI:10.1007/s00405-020-05965-1 PubMed PMID: 32253535; PubMed Central PMCID: PMC7134551.

5. Moein ST, Hashemian SM, Tabarsi P, Doty RL. Prevalence and reversibility of smell dysfunction measured psychophysically in a cohort of COVID-19 patients. Int Forum Allergy Rhinol. 2020 Oct;10(10):1127-1135. DOI: 10.1002/alr.22680. Epub 2020 Aug 19. PubMed PMID: 32761796; PubMed Central PMCID: PMC7436559.

6. COVID-19 and Your Health [Internet]. Centers for Disease Control and Prevention. 2021 [cited 2020 Sep 19]. Available from: https://www.cdc.gov/coronavirus/2019-ncov/testing/diagnostictesting.html.

7. Tan-Lim C, Burog A. Should electrochemiluminescence immunoassay (ECLIA) tests be used in the diagnosis of COVID-19? Psmid.org. 2020 [cited 2020 Sept 19] [about 19 pages. Available from: https://www.psmid.org/wp-content/uploads/2020/08/ECLIA-20200823_180625.pdf.

8. Klopfenstein T, Kadiane-Oussou NJ, Toko L, Royer PY, Lepiller Q, Gendrin V, Zayet S Features of anosmia in COVID-19. Med Mal Infect. 2020 Aug;50(5):436-439. doi: 10.1016/j. medmal.2020.04.006. Epub 2020 Apr 17. PubMed PMID: 32305563; PubMed Central PMCID: PMC7162775.

9. Eliezer M, Hautefort C, Hamel A-L, Verillaud B, Herman P, Eloit C. Sudden and complete olfactory loss of function as a possible symptom of COVID-19. JAMA Otolaryngol Head Neck Surg. 2020 Jul;146(7):674-675. DOI:10.1001/jamaoto.2020.0832 PubMed PMID: 32267483.

10. Galougahi MK, Ghorbani J, Bakhshayeshkaram M, Naeini AS, Haseli S. Olfactory bulb magnetic resonance imaging in SARS-CoV-2-induced anosmia: the first report. Acad Radiol. 2020;27(6):892-893. DOI:10.1016/j.acra.2020.04.002 PubMed PMID: 32295727 PubMed Central PMCID: PMC7151240.

11. Chiu A, Fischbein N, Wintermark M, Zaharchuk G, Yun P, Zeineh M. COVID-19-induced anosmia associated with olfactory bulb atrophy. Neuroradiology. 2021 Jan;63(1):147-148. DOI:10.1007/ s00234-020-02554-1 PubMed PMID: 32930820 PubMed Central PMCID: PMC7490479.

12. Buschhüter D, Smitka M, Puschmann S, Gerber JC, Witt M, Abolmaali ND, Hummel T. Correlation between olfactory bulb volume and olfactory function. Neuroimage. 2008 Aug 15;42(2):498 502. doi: 10.1016/j.neuroimage.2008.05.004. Epub 2008 May 10. PubMed PMID: 18555701

13. Mueller A, Rodewald A, Reden J, Gerber J, von Kummer R, Hummel T. Reduced olfactory bulb volume in post-traumatic and post-infectious olfactory dysfunction. Neuroreport. $2005 \mathrm{Apr}$ 4;16(5):475-8. doi: 10.1097/00001756-200504040-00011. PubMed PMID: 15770154

14. Rombaux $P$, Mouraux A, Bertrand B, Nicolas G, Duprez T, Hummel T. Olfactory function and olfactory bulb volume in patients with postinfectious olfactory loss. Laryngoscope. 2006 Mar;116(3):436-9. DOI: 10.1097/01.MLG.0000195291.36641.1E. PubMed PMID: 16540905.

15. Yao L, Yi X, Pinto JM, Yuan X, Guo Y, Liu Y, Wei Y. Olfactory cortex and Olfactory bulb volume alterations in patients with post-infectious Olfactory loss. Brain Imaging Behav. 2018 Oct;12(5):1355-1362. DOI: 10.1007/s11682-017-9807-7. PubMed PMID: 29234959.

16. Han AY, Mukdad L, Long JL, Lopez IA. Anosmia in COVID-19: mechanisms and significance. Chem Senses. 2020 Jun 17:bjaa040. DOI: 10.1093/chemse/bjaa040. Epub ahead of print. PubMed PMID: 32556089; PubMEd Central PMCID: PMC7449368.

17. Butowt R, von Bartheld C. Anosmia in COVID-19: underlying mechanisms and assessment of an olfactory route to brain infection. Neuroscientist. 2020 Sep 11:107385842095690. DOI:10.1177/1073858420956905 PubMed PMID:32914699 PubMed Central PMCID:PMC7488171.

18. Moein ST, Hashemian SM, Mansourafshar B, Khorram-Tousi A, Tabarsi P, Doty RL. Smell dysfunction: a biomarker for COVID-19. Int Forum Allergy Rhinol. 2020 Aug;10(8):944-950. DOI: 10.1002/alr.22587. Epub 2020 Jun 18. PubMed PMID: 32301284; PubMed Central PMCID: PMC7262123.

19. Widespread smell testing has limited application as a screening tool for COVID-19 [Internet] Entuk.org. 2021 [cited 2021 Jan 29]. Available from: https://www.entuk.org/sites/default/files/ ENT\%20UK\%20and\%20BRS\%20statement $\% 20-\% 20$ widespread $\% 20$ smell\%20testing $\% 20$ has\%20limited\%20application\%20as\%20a\%20screening\%20tool\%20for\%20COVID-19.pdf.

20. Evidente VGH, Esteban RP, Hernandez JL, Natividad FF, Advincula J, Gwinn-Hardy K, Hardy J, Singleton A, Singleton A. Smell testing is abnormal in 'lubag' or X-linked dystoniaparkinsonism: a pilot study. Parkinsonism Relat Disord. 2004 Oct;10(7):407-10. DOI:10.1016/j. parkreldis.2004.04.011 PubMed PMID:15465396.

21. David JF, Campomanes BSA, Dalupang Jl, Loberiza FV. -Smell Identification Test (-SIT). Philipp J Otolaryngol Head Neck Surg. 1994;14:62-68. [cited 2020 Sep 19] Available from: https://pjohns.

22. Hummel T, Rissom K, Reden J, Hähner A, Weidenbecher M, Hüttenbrink KB. Effects of olfactory training in patients with olfactory loss. Laryngoscope. 2009 Mar;119(3):496-9. DOI: 10.1002/ lary.20101. PubMed PMID: 19235739.

23. Altundag A, Cayonu M, Kayabasoglu G, Salihoglu M, Tekeli H, Saglam O, Hummel T. Modified olfactory training in patients with postinfectious olfactory loss. Laryngoscope. 2015 Aug;125(8):1763-6. doi: 10.1002/lary.25245. Epub 2015 Jun 2. PubMed PMID: 26031472.

24. Surburg H, Panten J. Common Fragrance and Flavor Materials: Preparation, Properties and Uses. 6 th ed. Wiley; 2016.

25. Smell Training Techniques to Do at Home | Olfactory Training |AbScent [Internet]. Abscent.org. 2021 [cited 2020 Sep 30]. Available from: https://abscent.org/learn-us/smell-training. 